\title{
An Overview of Dynamic Contact Resistance Measurement of HV Circuit Breakers
}

\author{
A. A. Bhole $\cdot$ W. Z. Gandhare
}

Received: 20 January 2013/Accepted: 12 November 2014/Published online: 30 January 2015

(C) The Author(s) 2015. This article is published with open access at Springerlink.com

\begin{abstract}
With the deregulation of the electrical power industry, utilities and service companies are operating in a changing business environment. High voltage circuit breakers are extremely important for the function of modern electric power supply systems. The need to predict the proper function of circuit breaker grew over the years as the transmission networks expanded. The maintenance of circuit breakers deserves special consideration because of their importance for routine switching and for protection of other equipments. Electric transmission system breakups and equipment destruction can occur if a circuit breaker fails to operate because of a lack of preventive maintenance. Dynamic Contact Resistance Measurement (DCRM) is known as an effective technique for assessing the condition of power circuit breakers contacts and operating mechanism. This paper gives a general review about DCRM. It discusses the practical case studies on use of DCRM for condition assessment of high voltage circuit breakers.
\end{abstract}

Keywords Circuit breaker testing .

Dynamic contact resistance measurement .

Metallic fluorides · Ultra capacitors

\footnotetext{
A. A. Bhole $(\bowtie)$

Department of Electrical Engineering, Government College of Engineering, Aurangabad, Osmanpura, Aurangabad,

Maharashtra, India

e-mail: bholeanita66@gmail.com

W. Z. Gandhare

Department of Electrical Engineering, Government College of Engineering, Amravati, Maharashtra, India
}

\section{Introduction}

A circuit breaker is an important equipment to power electric networks. Its importance is due to the role it is playing. According to CIGRE report [1], more than $90 \%$ of circuit breaker failures are due to mechanical causes. In view of this, circuit breakers are primarily mechanical devices that are performing an electric function. Hence it is imperative to assure its proper operation. This is only possible by applying suitable maintenance. Various utilities, people and organizations have different viewpoints on and approaches to maintenance strategies. Testing and maintenance methodologies have changed over the years and in all likelihood will continue to evolve as new technologies become available. Condition-based maintenance is being used more and more. It provides excellent opportunities to improve reliability and cut costs, but it requires effective diagnostic methods.

In POWERGRID, there have been failures of breakers due to damages in components in the interrupting chambers much before 10 years, that is, before carrying out the first major overhaul. Defects were noticed in the components of few circuit breakers before completion of 10 years, whereas few circuit breakers which were 17 to 20 years in service were healthy. Power Grid Corporation India Ltd. (PGCIL) then started Dynamic Contact Resistance Measurement (DCRM) for diagnostic testing to decide for overhauling [2].

\section{Static Contact Resistance Measurement}

The modern High Voltage SF6 circuit breakers have two parallel contact sets. The main contacts are low resistance contacts, which are silver plated, whereas arcing contacts 
are of tungsten-copper which helps in initiating arc quenching and current interruption. Measurement of the static contact resistance with the breaker in closed position gives the resistance of main contacts only because the arcing contacts are bypassed. Healthiness of main contacts only gets checked during this test. The minimum dc test current should be used according to manufactures specification; however, the IEC and ANSI recommended levels are: 50 A IEC 60694 and 100 A ANSI.

Static contact resistance is measured by injecting a dc current through the breaker and measuring the milli-voltage drop. A four wire measurement method is used. The breaker must be in the closed position. If low resistance readings are obtained when testing the breaker contact resistance using a low current, then it is recommended to re-test the contacts at a higher current. A higher current will have the ability to overcome connection issues and oxidation on terminals, where a lower current may produce higher readings under these conditions [3].

\section{Dynamic Contact Resistance Measurements}

The limitation of static contact resistance measurement is that it does not give information about the arcing contact condition. Erosion of arcing contact, contact misalignment, damage to driving mechanism cannot be detected from static contact resistance measurement. Dynamic contact resistance measurement for circuit breakers was introduced in 1992.

The DCRM test method is very suitable for diagnostic testing. Figure 1 shows the schematic diagram for DCRM. Tests are conducted by injecting $100 \mathrm{~A}$ dc current through the breaker and measuring the voltage drop and current, while the breaker is operated with rated speed during closeopen operation. DCRM is not measured during open-close operation. The measurement in this condition is impractical because sudden change of resistance variation from infinite to the arcing contact resistance is difficult to measure. Secondly, the transient dc current at the moment of arcing contact touch generates the undesired noise and therefore measurement is not correct. The breaker analyzer then calculates and plots resistance as a function of time. Linear or rotary contact travel sensor is used depending on breaker technology for recording contact movement. The resistance at each point of contact can be calculated if contact movement is recorded. Test kit uses analyzer with a sampling frequency of $10 \mathrm{kHz}$. Measurements are recorded with a resolution of $100 \mu$ s to record resistance values with precision as well as transfer of current from arcing to main contacts and vice versa. The time interval between close trip operations is kept $300 \mathrm{~ms}$ to get good signature. The variations in the measured resistance versus time signature will be seen as a 'finger print' for the breaker contacts and can be used as benchmark for comparing with future measurements on the same breaker. This provides information on the condition of the breaker contacts and associated mechanism [2]. This method is used for contact diagnosis, and in certain cases it is also used to measure times. In SF6 and air-blast breakers the arcing contact is commonly made of tungsten-copper. This contact is burned off and becomes shorter for each live operation of the circuit breaker. With DCRM it is possible to reliably estimate the length of the arcing contact.

\section{Review on Dynamic Contact Resistance Measurement}

\section{Measurement at Low Speed}

It was observed by Landry et al. [4] that DCRM curves at rated speed were not reproducible from one test to another. It was difficult to identify the main contact part. It was anticipated that this phenomenon is caused by partial contact part and due to high contact speed and acceleration. They found that performance of DCRM at low contact speed of 0.2 and $0.15 \mathrm{~m} / \mathrm{s}$ were almost identical. At low contact speed, the DCRM curve was smoother and the main contact part can be easily identified. However, for some breaker mechanisms, the method is intrusive since some adjustments of the operating mechanism are required for low-speed breaker operation. There is a potential risk of damaging the operating mechanism when restoring it back in service. Also the DCRM at low speed may not give the correct information of the contacts because in service the circuit breaker is operated with rated speed only.

\section{DCRM in the Presence of Metallic Fluorides}

Metallic fluorides are usually present in the form of nonconductive dust powder deposited on the breaker contacts. The effects of metallic fluorides on contact resistance have been dealt [5]. High resistance was observed on a capacitor bank circuit breaker which had undergone quite large number of operations. Short-circuit breaking tests have revealed that the presence of metallic fluorides does not decrease the breaker's breaking capacity. High contact resistance will appear when there is no scraping motion between contacts [6]. Static contact resistance measurements of the main contacts using conventional equipment injecting 10-A dc current was carried out as a first check. An extremely high value of the main contact resistance of the order of 4,500-6,000 $\mu^{\prime} \Omega$ was measured, which could be interpreted as defective contacts. A measurement method was developed by Michel Landry et al. to determine the reason for high resistance with the aim of 
Fig. 1 Schematic diagram of DCRM

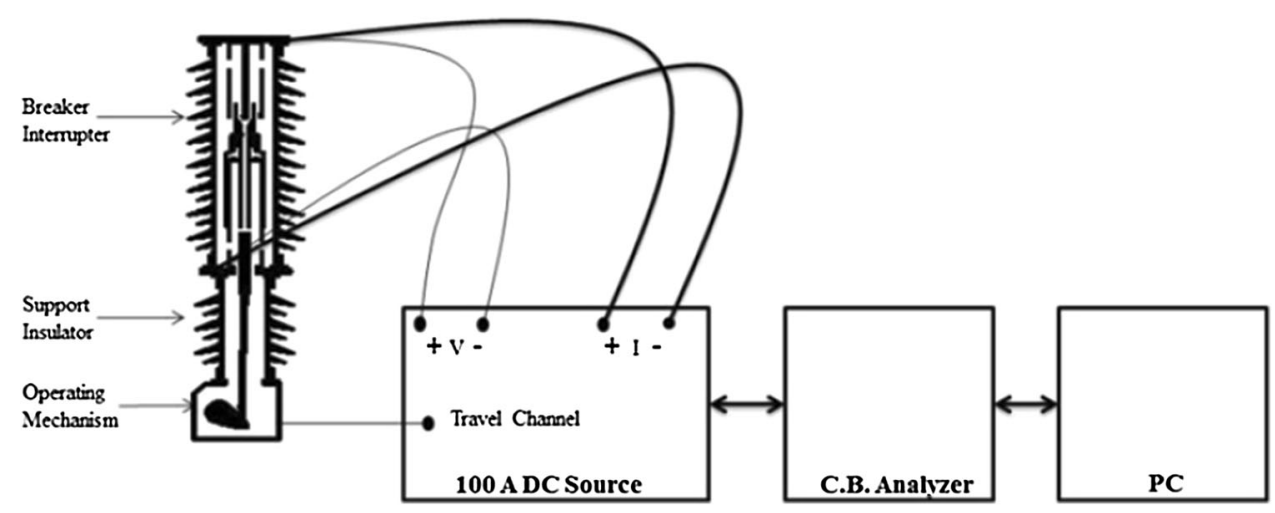

avoiding the dismantling of the breaker's interrupting chambers. The measuring system consists of three current sources connected in parallel for delivering the measuring current of 2800 A dc. Six 4/0 copper cables were used to carry the high dc current from source to the breaker terminals. A data acquisition system along with a measuring shunt of 51.32 ' $\Omega$ was used for recording the relevant signals. With the breaker contacts maintained closed, contacts heating at currents from $100 \mathrm{~A}$ to $2800 \mathrm{~A}$ for different intervals from 1-15 min were performed in order to vaporize the deposited metallic fluorides at the actual points of contact. DCRM for different currents were taken for each phase. Michel Landry et al. observed that 2800A current for at least $15 \mathrm{~min}$ was required to reduce the arcing contact resistance to an acceptable level [6].

\section{Low Resistance Meter with Ultra Capacitors}

The conventional method of DCRM measurement requires long, heavy cables to connect high current source to the breaker. Alternative is to move current source close to the circuit breaker by using heavy batteries, transformers $\mathrm{dc} / \mathrm{dc}$ etc. A paper [7] was published on the use of ultra capacitors as a current source. The batteries can be replaced with ultra capacitors and constant current charger which is light weight powerful current source capable to generate few hundred amperes. They developed a low resistance meter which was based on a large value capacitor with ultra-low internal resistance, a current switch, a charger for the capacitor plus control and a measurement circuitry allowing for a high dc current of about $250 \mathrm{~A}$ to be generated. This low resistance meter can be used for static and dynamic resistance measurements. The accuracy of measurement depends on the instrumentation used for voltage and current measurement.

\section{DCRM Signature Analysis}

Figure 2 shows a typical normal DCRM signature. DCRM can be called as an ECG of circuit breaker. The analysis software with a test kit can be used for analysis. Analysis of DCRM signatures requires knowledge of circuit breaker design, operating mechanism, and interrupter assembly and also expertise to conclude the cause. The shape of DCRM signature depends on the contact configuration, contact wipe, type of operating mechanism and other parameters like contact speed etc. Necessary measurements can be done by enlarging a portion of the graph and superimposing earlier signature to find deviations. Many parameters such as length of arcing contact, contact wipe and erosion of main and arcing contacts, contact misalignments, healthiness of linkage mechanism, main and arcing contact resistance, contact travel and speed etc. can be obtained from signature. Figure 3 shows the enlarged view of DCRM signature in the opening portion for a $400 \mathrm{kV}$ SF6 circuit breaker with spring-pneumatic mechanism. Length of arcing contact can be measured by placing the cursor on the travel curve at the point where resistance of arcing contact just begins to be visible and second curser at the point where the resistance begins to change to the contact opening status. The circuit breaker was designed for $140 \mathrm{~mm}$ of mechanism travel. From signature, travel of arcing contact is $11.79 \mathrm{~mm}$.

Linkage Ratio $=\frac{\text { Contact Travel }}{\text { Mechanism Travel }}=\frac{230}{140}=1.642$

Thus, Length of arcing contact $=11.79 \times 1.642=$ $19.35 \mathrm{~mm}$.

This is how by enlarging the signature in the trip free portion and knowing the design details of circuit breaker, length of arcing contact can be found out from the signature.

\section{Electromagnetic Forces on Contacts}

Design of contacts play a crucial role in circuit breaker. Contact force and actual contact area are two important parameters that greatly influence the value of contact resistance. The contact resistance is given by

$R_{T}=\frac{\rho}{2} \sqrt{\frac{\pi k H}{F_{T}}}+R_{F}$ 
Fig. 2 Normal DCRM signature

Fig. 3 Enlarged view of DCRM in opening portion
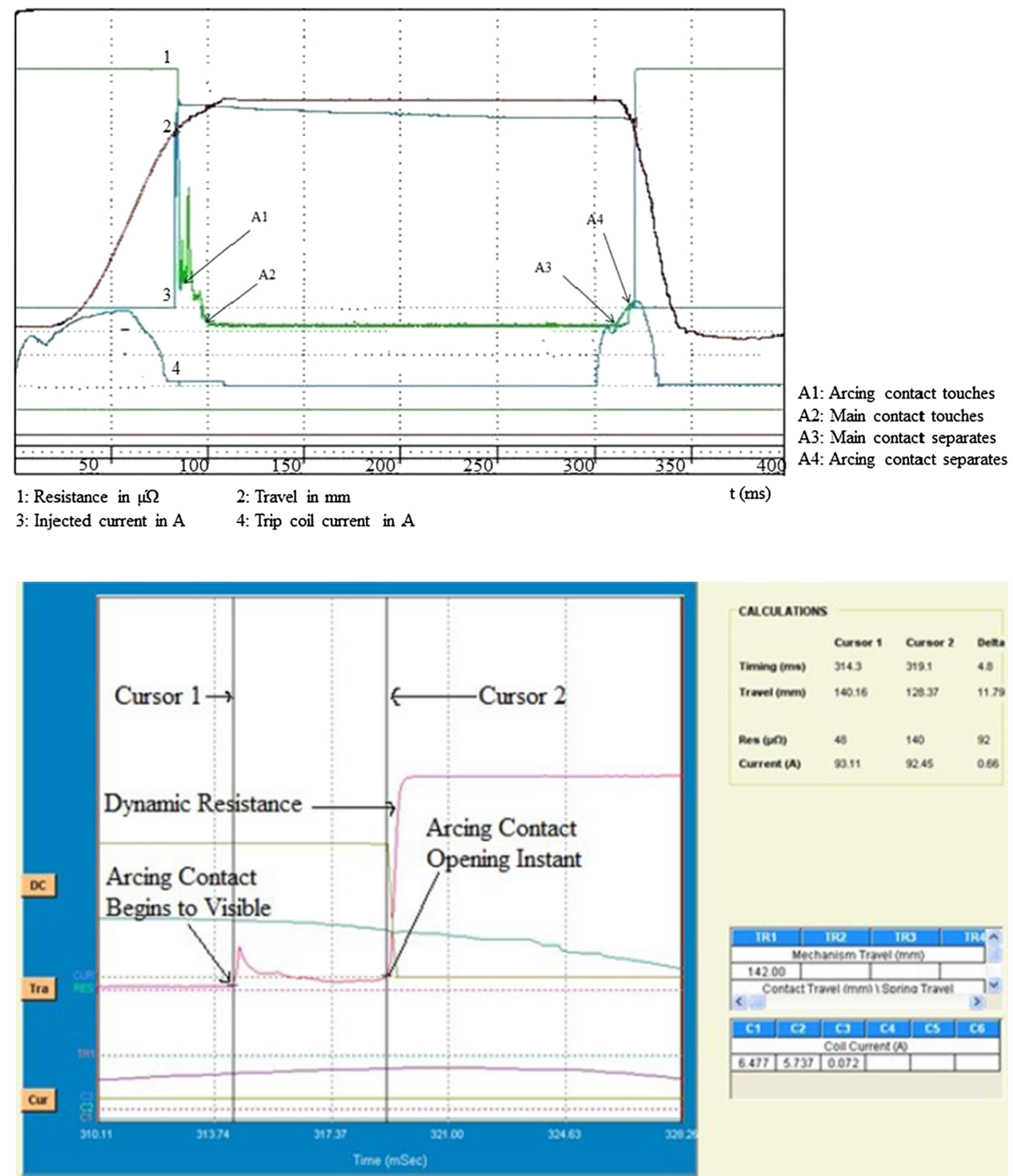

where $\mathrm{H}$ is the material hardness; $\mathrm{K}$, the constant between 0.1 and $0.3 ; \rho$, the resistivity of contact material; $R_{F}$, the film resistance; and $\mathrm{F}_{\mathrm{T}}$ is the total force acting on a contact.

The constriction at the point of contact is responsible for the contact resistance and consequently for the heat being generated at the contacts and also is the source of electromagnetic force acting upon the contact structure.

For a circular cluster contact there is attraction force $\left(\mathrm{F}_{\mathrm{A}}\right)$ in addition to repulsive force $\left(\mathrm{F}_{\mathrm{R}}\right)$ and contact spring force $\left(\mathrm{F}_{\mathrm{S}}\right)$ on the fingers of the contact. Thus the total force $\left(\mathrm{F}_{\mathrm{T}}\right)$ acting on a contact is given by

$\mathrm{F}_{\mathrm{T}}=\mathrm{F}_{\mathrm{S}}+\mathrm{F}_{\mathrm{R}}-\mathrm{F}_{\mathrm{A}}$

For a properly designed contact, attraction force should be greater than repulsive force. A sulfide coat is formed on a silver contact surface of a SF6 circuit breaker when it is subjected to arcing. This increases the contact resistance if there is no scraping or wiping motion between the contacts. However this sulfide film is easily removed by slight friction and it may even be decomposed by heat. For a circular cluster type contact, there is a force of attraction between two opposite fingers, where current is flowing in the same direction of each contact. This force of attraction for contact having ' $n$ ' fingers and distance ' $d$ ' between fingers with a current of $I / n$ through each finger is given by

$F_{A}=0.102(n-1)\left(\frac{1}{n}\right)^{2}\left(\frac{1}{d}\right)$

This current is inversely proportional to the distance ' $d$ ' between fingers as shown in the Fig. 4. These forces tend to pinch the moving finger contacts on the fixed contact, thus reducing the contact resistance. Also, it improves the wiping action on the contact surface removing sulfide coat [8]. In view of this, contacts of a circuit breaker should be 


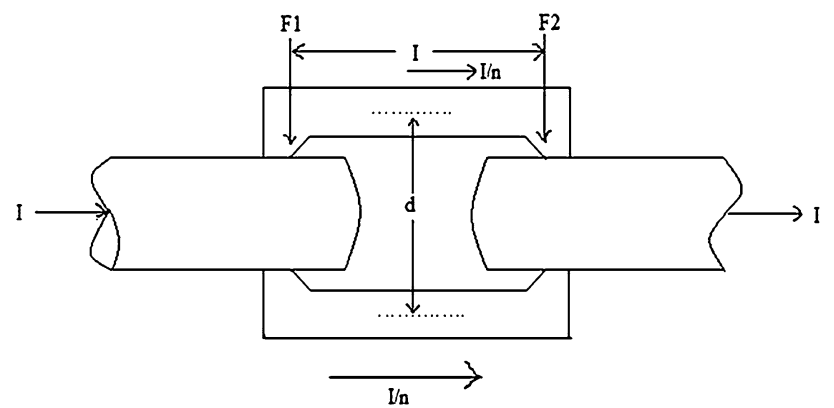

Fig. 4 Force of attraction on circular cluster contact

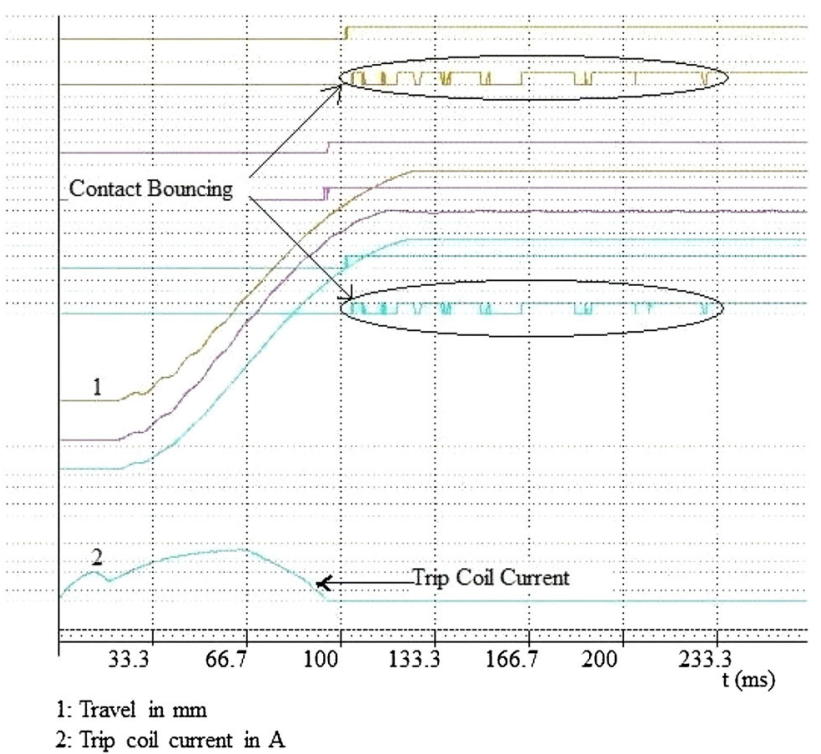

Fig. 5 Contact bouncing after closing cycle on 400 kV SF6 circuit breaker

properly designed for a wiping action so as to minimize the problem of metallic fluoride.

\section{Case Studies}

Condition assessment of circuit breaker through DCRM technique is being used by POWERGRID and various utility companies in India. Following case studies depicts the use of DCRM signature in detecting the defects at early stage in circuit breakers.

\section{Case No. 1}

During closing operation, contact bouncing was seen (Fig. 5) in no load-closing characteristic for longer duration for a $400 \mathrm{kV}$ SF6 circuit breaker at manufacture works. The bouncing was taking place after completion of mechanical contact travel. Following steps were taken to analyze the problem.

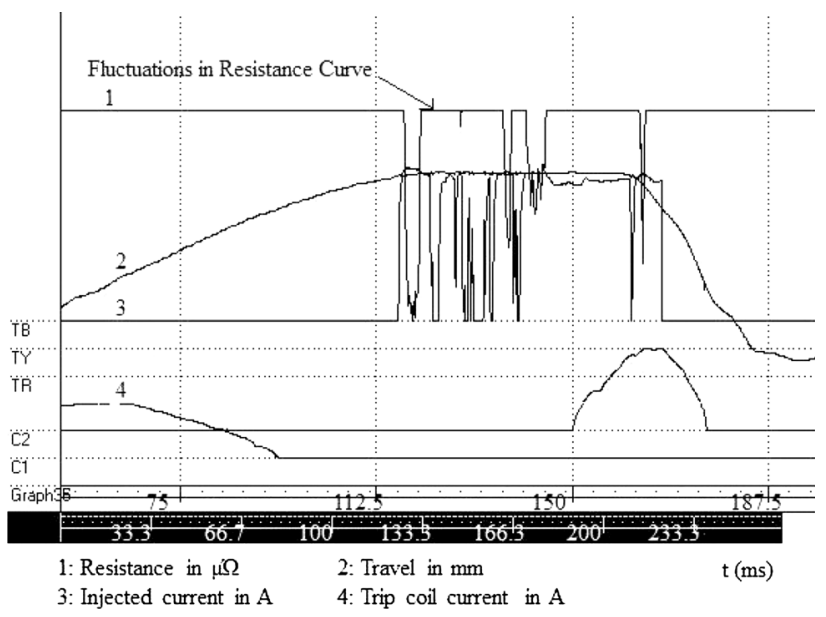

Fig. 6 DCRM signature showing fluctuation $s$ in resistance curve of $\mathrm{B}$ phase front side interrupter

1. The external connections were confirmed normal by re-verification. The test leads connecting main contact to analyzer were checked. To eliminate electrical signaling fault, the test was repeated with different analyzer. But same problem was observed. It was confirmed that the problem is inside the interrupter assembly.

2. Static contact resistance of the pole was verified and found to be very high $120-160 \mu^{\prime} \Omega$.

3. The DCRM test of B-phase front side interrupter was conducted to verify the contact bouncing seen in noload closing characteristic.

4. DCRM test showed lot of fluctuations in the current and resistance curve in the steady state part of the contact travel curve seen in Fig. 6.

5. The rear side of same pole was also showing abnormal DCRM signature, even though no abnormal contact bounce was seen in no-load closing operation.

6. After investing subassemblies in steps, the final cause was detected in moving contact assembly. The joint of puffer cylinder and cylinder support was found loose fitted. Tightening Torque was not applied during assembly.

Case No. 2

Contact mismatch was observed in opening operation for a $245 \mathrm{kV}$ SF6 circuit breaker. The mismatch was not getting adjusted with spring and coil adjustments. After analyzing the normal speed time graph following points were noticed

1. Abnormal contact bouncing in closing for longer duration in $\mathrm{R}$ and $\mathrm{Y}$ poles for more than $5 \mathrm{~ms}$ was observed. 


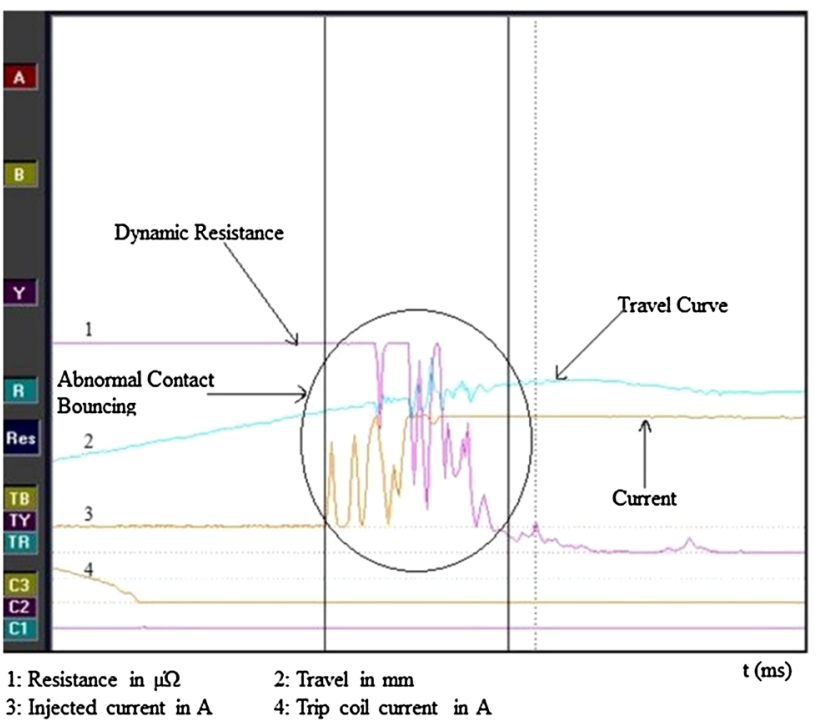

Fig. 7 DCRM of R-pole in closing part

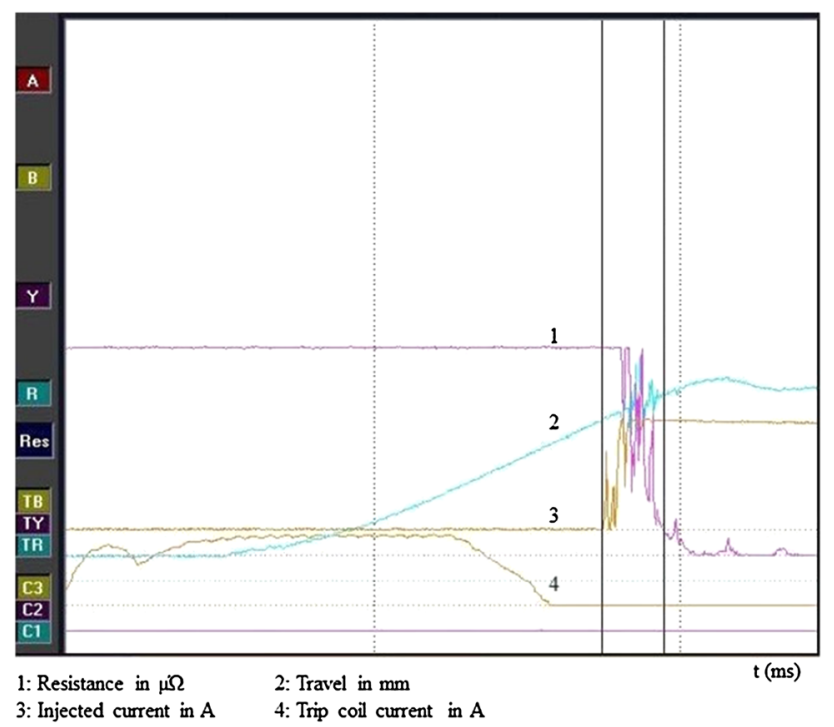

Fig. 8 DCRM of Y-pole in closing part

2. The wiping was less in opening operation for $\mathrm{R}$ and $\mathrm{Y}$ pole compared to B pole.

The DCRM signatures were obtained for all three phases. The signature was analyzed for the closing and tripping part of the signature. Abnormality in current as well as resistance and travel curve was observed for $\mathrm{R}$ and $\mathrm{Y}$ pole as seen in Figs. 7 and 8. Figure 9 shows the DCRM of R-pole in tripping part. After opening the circuit breaker, it was observed that $145 \mathrm{kV}$ arcing contact was fitted in place of $245 \mathrm{kV}$ arcing contact as seen in Fig. 10. Signatures were normal after fitting proper arcing contact.

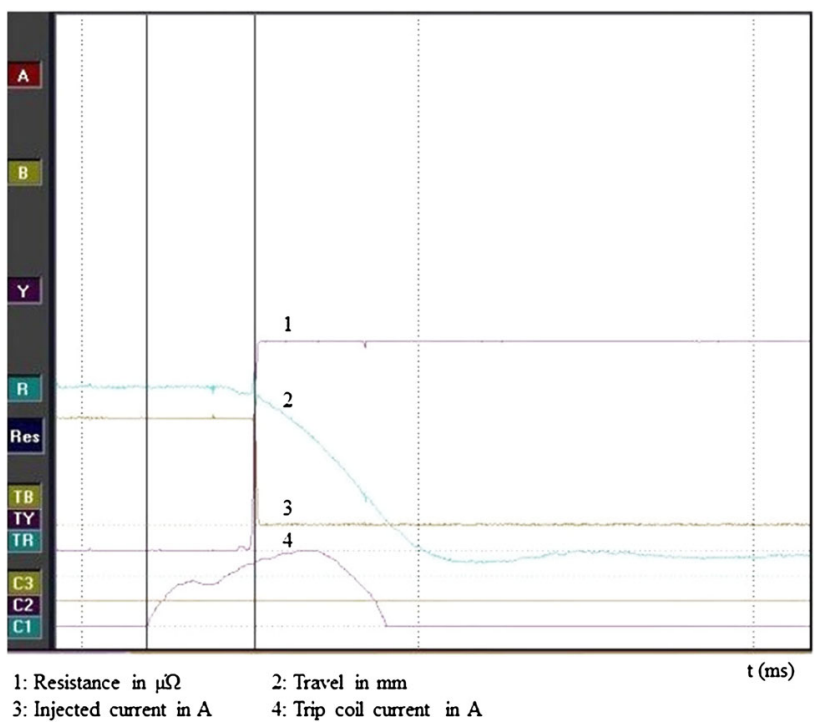

Fig. 9 DCRM of R-pole in tripping part

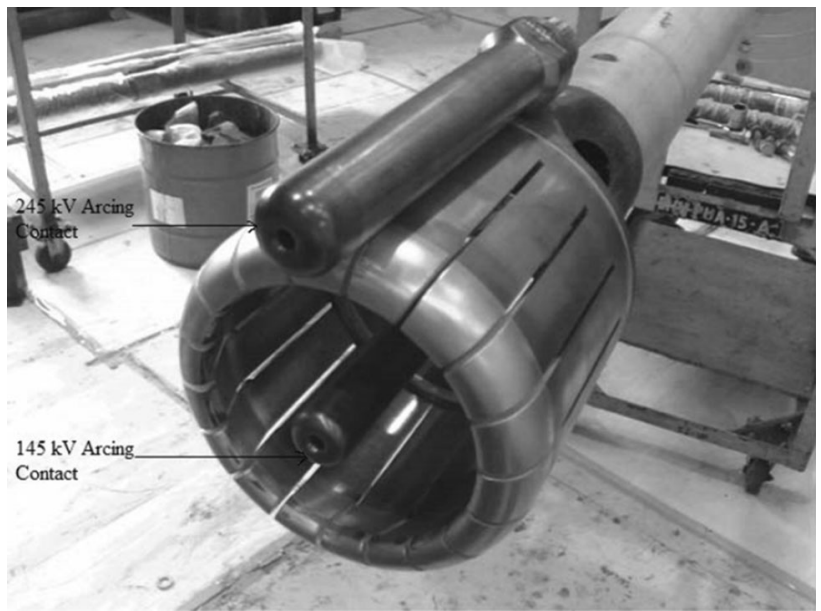

Fig. 10 Wrong assembly arcing contact

Case No. 3

The no load operation graph of a $245 \mathrm{kV}$ SF6 circuit breaker in closing was normal as seen in Fig. 11. However, DCRM (Fig. 12) was showing contact bouncing and current breaking in closing part. The DCRM for the same breaker in opening is shown in Fig. 13. Again the closing operation was carried out and bouncing was seen in the closing graph in Fig. 14. After opening the interrupter, it was observed that the moving arcing contact was became loose. This indicates that while assembling the required tightening torque was not applied and in consequent mechanical operations it started becoming more and more loose. Normal signature was obtained after rectification of the problem. 


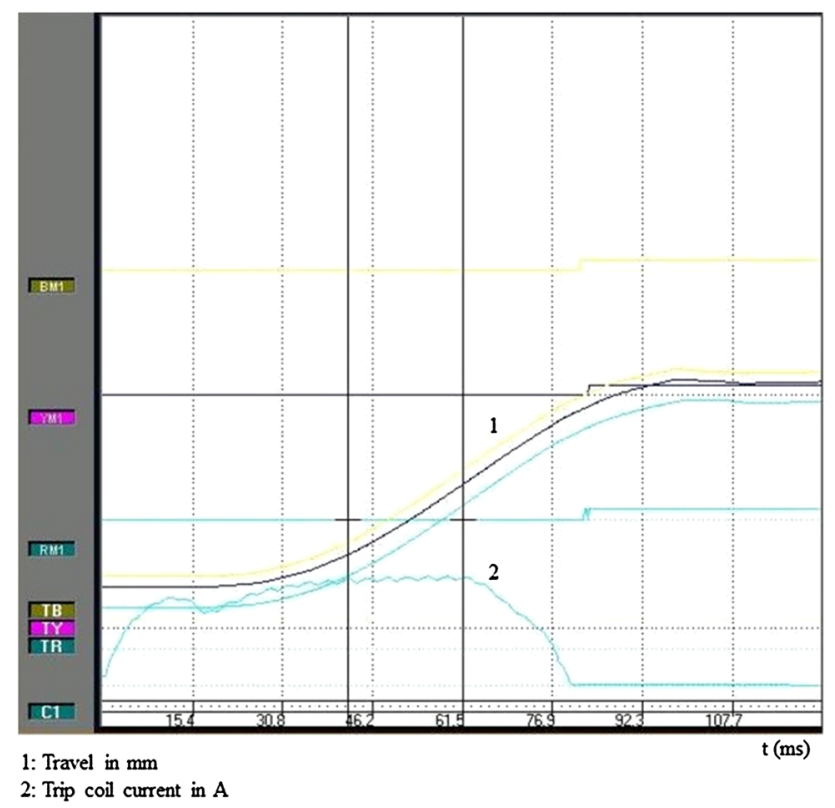

Fig. 11 No load operation graph of 245 kV SF6 circuit breaker

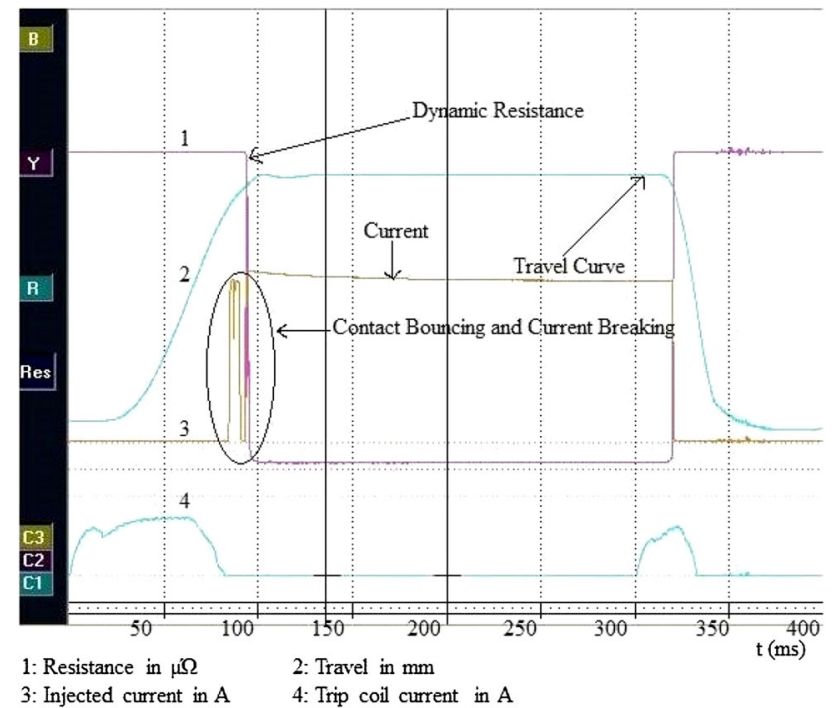

Fig. 12 Complete DCRM of $245 \mathrm{kV}$ SF6 circuit breaker

Case No. 4

In June 2009, at $400 \mathrm{kV}$ substation Waluj, Aurangabad, contact resistance measurement of R-pole of a $220 \mathrm{kV} \mathrm{SF6}$ circuit breaker of $200 / 33 \mathrm{kV}, 50 \mathrm{MVA}$ transformer was showing a contact resistance of the order of $200 \mu^{\prime} \Omega$. Contact resistance value was showing higher value for each operation of circuit breaker. It was then decided to conduct DCRM. As shown in Fig. 15, DCRM was showing lot of

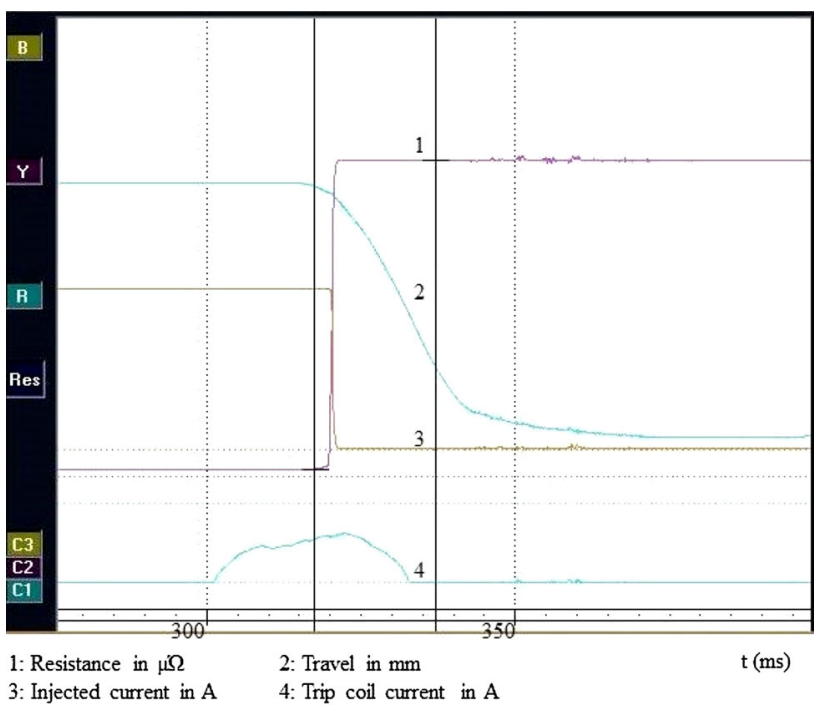

Fig. 13 Opening part of DCRM of 245 kV SF6 circuit breaker

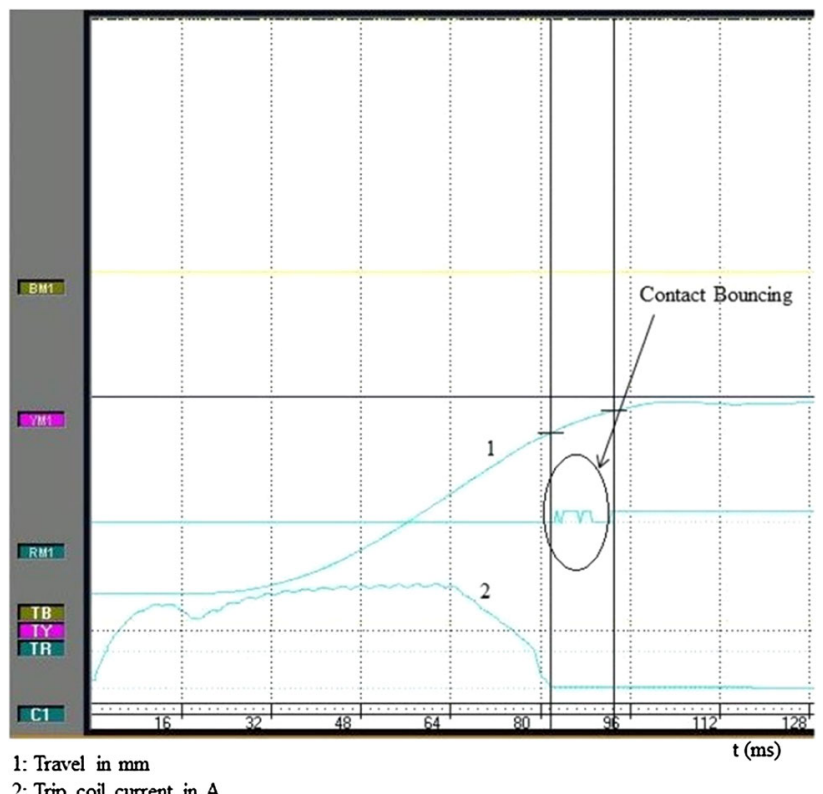

Fig. 14 No load operation graph of 245 kV SF6 circuit breaker showing contact bouncing

fluctuations in main contact region of the signature. After verification of connections, again the DCRM was repeated. It was showing the similar signature. It was then decided to overhaul the R-pole. After opening, it was found that the ring connecting PTFE nozzle of main contact became loose and scratch marks were also seen in Fig. 16. After attending the problem, the signature was found to be normal. 


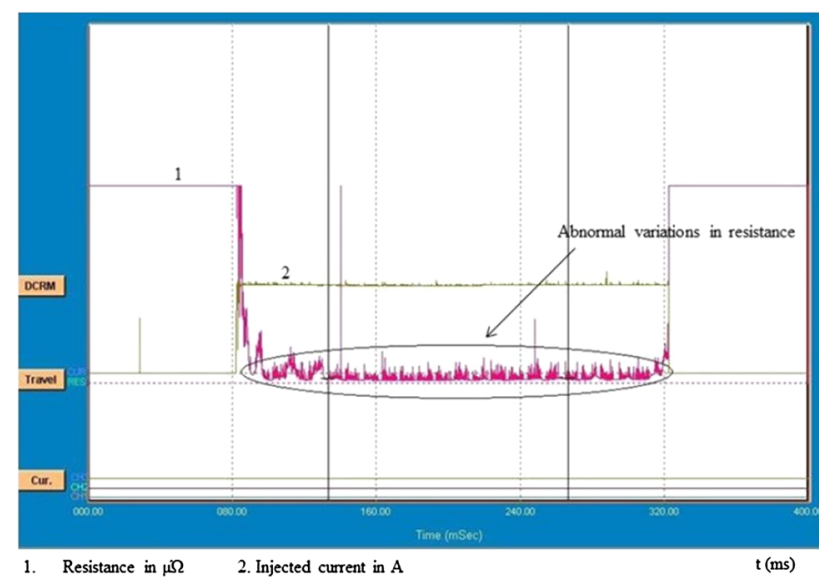

Fig. 15 DCRM of $220 \mathrm{kV}$ circuit breaker showing abnormal variation is resistance

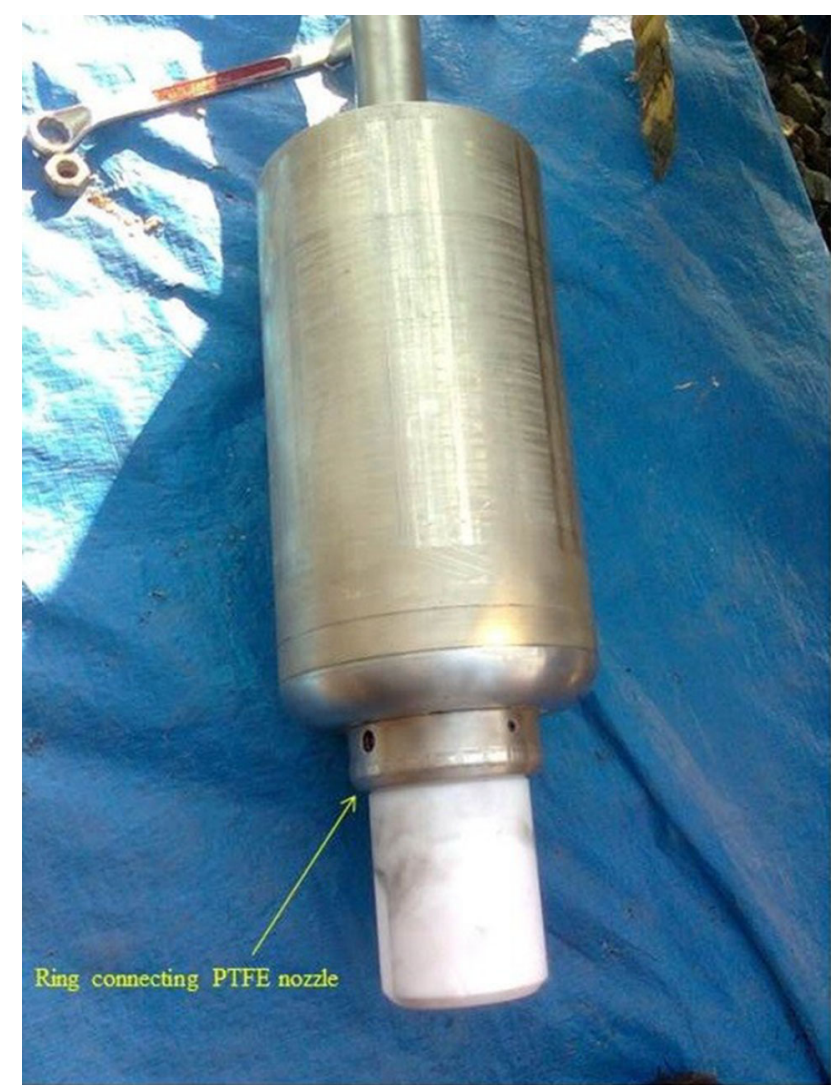

Fig. 16 Loose ring connecting PTFE nozzle of main contact 11

\section{Conclusions}

In this paper, an overview of dynamic contact resistance measurement is presented. DCRM allows the evaluation of the wear and tear of the arcing and main contacts without opening the CB. It helps to save on the cost of an extended down time that is caused by complete disassembly of the CB to visually assess the state of the arcing contact. Electrical lifetime can be calculated by analyzing DCRM. Four case studies were studied. DCRM at rated speed \& injection of $100 \mathrm{~A}$ dc current was carried out. Measurements were recorded with a resolution of $100 \mu$ s with a sampling frequency of $10 \mathrm{kHz}$. It is observed that DCRM is useful to the manufacturers as the manufacturing error can be detected before dispatch. Wipe adjustment, improper torque for tightening, assembly of wrong arcing contacts, etc. can be detected at the works only avoiding further complications. Utility companies like PGCIL and state transmission companies can avoid major breakdown through condition assessment of high voltage circuit breakers. However, analysis of DCRM signature needs knowledge of anatomy of $\mathrm{CB}$ that is $\mathrm{CB}$ design, operating mechanism etc. to conclude the case. DCRM is found to be a powerful diagnostic tool for circuit breaker health management.

Open Access This article is distributed under the terms of the Creative Commons Attribution License which permits any use, distribution, and reproduction in any medium, provided the original author(s) and the source are credited.

\section{References}

1. CIGRE SC13, High Voltage Circuit Breaker Reliability Data for Use in System Reliability Studies (CIGRE Publication, Paris, France, 1991)

2. N.S. Sodha, S. Singh, S. Victor, R.K. Tyagi, Condition assessment of EHV class circuit breakers using dynamic contact resistance measurement techniques, in Proceedings of CIGRE Session, A3205, 2012

3. www.megger.com/us

4. M. Landry, A. Mercier, G. Ouellet, C. Rajotte, J. Caron, M. Roy, F. Brikci, A new measurement method of the dynamic contact resistance of HV circuit breakers, in Proceedings of CIGRE Session, A3-112, 2004

5. M. Landry, J. Caron, G. Ouellet, R. Bastien, A new method for measuring the main contact resistance of 25-kV SF Gas FB4-type circuit breakers. Presented at the Circuit Breaker Test Maintenance Conference, Jackson, MS, September 6-8, 1999

6. M. Landry, O. Turcotte, F. Brikci, A complete strategy for conducting dynamic contact resistance measurements on HV circuit breakers. IEEE Trans. Power Delivery 23(2), 710-716 (2008)

7. Z. Stanistic, R. Neimanis, A new ultra lightweight method for static and dynamic resistance measurements, IEEE Transactions 2010

8. R.D. Garzon, Contact theory, in high voltage circuit breakers, design and applications, 2nd edn. (Marcel Dekker, New York, 2002), pp. 198-210 